\title{
Discurso de recepción de Medalla Rectoral del profesor Alberto van Klaveren
}

La distinción que hoy me otorga la Universidad de Chile constituye para mí un honor impensado. Las palabras no son suficientes para expresar mi gratitud hacia esta casa de estudios superiores, representada por su Rector, doctor Ennio Vivaldi, y hacia su Consejo, que se ha dignado a aceptar la propuesta que hiciera el Instituto de Estudios Internacionales, a través de su Directora, la profesora Dorotea López. Recibir esta medalla en presencia de una audiencia tan distinguida y cercana, acrecienta mi reconocimiento. Gracias a todos ustedes por su asistencia a un acto tan significativo, en fechas complicadas, marcadas muchas veces por viajes y encuentros familiares. En especial, mi sincero reconocimiento, por su generosa presentación, a la profesora Rose Cave, académica de esta Casa y colega y amiga de tantos años.

Recibir esta medalla junto a la profesora María Teresa Infante no es una mera coincidencia. Nos une una larga carrera compartida, primero en esta Universidad y luego en la Cancillería. Su solvencia profesional, su capacidad de trabajo, su compromiso con la academia y su espíritu de servicio público, han constituido un apoyo invaluable y una referencia obligada para quien habla. Es un verdadero honor compartir esta distinción con ella.

$\mathrm{Al}$ ingresar hace ya muchos años al primer año de la carrera de Derecho en esta Universidad, nunca pensé que iba a permanecer vinculado a esta casa de estudios toda mi vida. Ya consideraba un privilegio haber podido ingresar a la primera Facultad de Ciencias Jurídicas de la República, primera no solo por razones históricas, sino por el aporte permanente que estaba haciendo al desarrollo de esta área del conocimiento y del país. Ahí pude tomar clases con grandes maestros, juristas que dejaron una huella indeleble en nuestro país. Hombres y, en esa época en mucho menor medida, mujeres, que ocuparon posiciones destacadas en nuestro devenir. Ahí conocí un mundo académico y político, que reflejaba la diversidad intelectual y, en cierta medida, social, de Chile. Ahí fui expuesto a las teorías más diversas sobre las distintas ramas del derecho, la historia, la filosofía, la ciencia política, la sociología y las relaciones internacionales. Y ahí pude realizar mi vocación internacional, una vocación que refleja mi propio origen y que fue cultivándose en mi hogar y en mi formación previa. 
Quiero dejar constancia de mis múltiples deudas, personales, intelectuales y profesionales. En primer lugar, con mis padres, que después de una experiencia traumática durante la guerra que les tocó vivir en su país, Holanda, y ante el temor de una nueva conflagración mundial, decidieron emigrar a Chile, con la firme convicción de asentar para siempre a su pequeña familia en este país, proyecto que vieron realizado. Fueron ellos los que me hicieron entender que todo lo que sucedía en el mundo nos tenía que importar, y que el país que nos acogía merecía respeto y compromiso. Deuda con mi esposa, quien con paciencia, sabiduría y amor me ha acompañado y apoyado en todas mis aventuras profesionales e intelectuales. Deuda con mis hijos, que nos han llenado de satisfacciones y afectos. Deuda con mis maestros, entre los cuales destaco especialmente a Gustavo Lagos Matus, quien con gran generosidad me introdujo a la disciplina de las relaciones internacionales y quien me enseñó, con su propio ejemplo, que no existe una brecha inexpugnable entre la teoría y la práctica. Deuda con profesores muy notables que tuve en la Facultad de Derecho de la Universidad de Chile, con colegas del Instituto de Estudios Internacionales y con destacados académicos que me acompañan en esta ocasión. Deuda con los Presidentes de Chile que me honraron con sus nombramientos; con los Cancilleres de Chile, con los que he tenido la oportunidad de trabajar y que invariablemente me dieron su confianza. Y con todos mis colaboradores en las instituciones en las que he podido servir, especialmente el Instituto de Estudios Internacionales y la Facultad de Derecho de la Universidad de Chile, y el Ministerio de Relaciones Exteriores.

Citar a todos de quienes he aprendido y con los que he trabajado llevaría más tiempo del que dispongo. Pero quiero dejar constancia de que cada uno de nosotros somos el producto de muchos otros que nos antecedieron. Somos también tributarios del trabajo colectivo, de los equipos que integramos. Y, como profesor, no puedo dejar de mencionar mi aprecio y respeto por los estudiantes que he tenido, con los que también he seguido aprendiendo.

Siempre he creído que las oportunidades asumen un papel crucial para explicar una trayectoria profesional. Yo tuve la oportunidad de combinar la actividad académica con la diplomacia; el estudio y el trabajo en otros países y en Chile; la universidad con la Cancillería. Esta experiencia ha sido enormemente enriquecedora, aunque soy consciente de que la función pública a veces limita la visión académica y que esta última puede también llevar a deformaciones en el ámbito diplomático.

Hace unas décadas, muchos estábamos preocupados por la concentración del poder en unos pocos actores en el mundo; por la hegemonía que algunas potencias ejercían sobre el resto. Hoy la preocupación es otra. Se habla del 
mundo de nadie, un mundo sin un centro de gravedad y sin principios y valores universalmente compartidos, en que ninguna potencia o grupo de potencias logra imponerse sobre el resto. Se habla del fin del poder, en que los poderes de antaño se ven desafiados por un conjunto crecientemente heterogéneo de actores, muchos de ellos informales y algunos de ellos incontrolables. Se habla, también, del fin del orden internacional liberal que fue construido trabajosamente después de la Segunda Guerra Mundial.

Seguimos viviendo en un sistema internacional en que no hay una autoridad superior. Pero ya no es un sistema anárquico. Más bien, es una comunidad descentralizada, que no equivale al caos. Existen límites para el comportamiento de los Estados. Hay reglas que los contienen. Y esas reglas provienen del derecho internacional. Un derecho con fuentes diversas y hasta inciertas; con normas que a veces son vagas o ambiguas, porque tratan de reflejar consensos difíciles de alcanzar; con principios que pueden ser contradictorios, que reflejan épocas distintas y relaciones de poder a escala internacional. Un derecho que no posee una jerarquía clara de tribunales y otras instancias judiciales, y cuyos fallos quedan entregados a la voluntad de los países.

Con todas sus limitaciones, no se puede ignorar que ese derecho ha servido de marco para la actividad internacional a lo largo de los años y que los principios e ideas que le sirven de base tienen raíces que se remontan muy atrás en la historia. La misma interdependencia que caracteriza a nuestro sistema internacional sería inexplicable sin la existencia de normas que la regulan y que son observadas generalmente por Estados y otros actores internacionales. La mayor parte de las normas internacionales se observa regularmente. Las fronteras de los Estados son estables; para bien o, a veces, para mal, la soberanía de las naciones se respeta generalmente; las violaciones de los derechos humanos se denuncian internacionalmente y en muchos casos se persiguen; el comercio fluye de manera regular, y muchas instituciones internacionales cumplen sus objetivos.

Pero el derecho internacional no se restringe solo a un conjunto de normas y prácticas que surgen a través de procesos variados y complejos, y que van construyendo regímenes internacionales que regulan muchas áreas de la actividad internacional. Ya no es, como sucedía en la época de Hugo Grocio, un derecho sin tribunales. Más bien, una de las tendencias más marcadas que se observa en esta área es la creciente judicialización. No se trata solo de la multiplicación de órganos e instancias de solución de controversias, sino de la judicialización de las relaciones internacionales. Es decir, temas que históricamente quedaban entregados a la política internacional, a las políticas de defensa o 
que permanecían congelados en el escenario internacional, hoy son llevados a cortes u otras instancias de solución de controversias.

El derecho internacional no es un edificio normativo fijo. Es un cuerpo vivo en constante transformación, que refleja de manera imperfecta y no pocas veces con atraso, la propia evolución del sistema internacional. Pese a sus insuficiencias, constituye el único y generalmente aceptado medio para resolver los problemas globales. Ni la ideología ni la religión otorgan normas compartidas a nivel global; solo el derecho internacional tiene esa cualidad.

Estas disquisiciones son relevantes para nuestra política exterior. Chile ha estado histórica y activamente asociado a un sistema internacional fundado en principios, normas y valores compartidos. La vinculación creciente al mundo constituye un imperativo geográfico, político, económico, social y cultural. Nuestra condición de país abierto hace indispensable que utilicemos las ventajas de la globalización y contribuyamos a relativizar sus efectos adversos. Por ello, priorizamos el trabajo colectivo en la elaboración de normas, estándares e instituciones internacionales.

De allí que nuestra participación en los sistemas multilaterales, globales y regionales, donde se construyen las normas básicas de la convivencia internacional que contribuyen a proteger nuestros intereses. De allí, nuestro respeto al derecho internacional y la convicción de que los tratados internacionales constituyen los ejes estructurantes de nuestras relaciones con los países hermanos y el resto del mundo. De allí, nuestro compromiso con la solución pacífica de las controversias, que implica el rechazo al uso de la fuerza o su amenaza, como lo establece la Carta de las Naciones Unidas, así como el convencimiento de que la diplomacia y el derecho internacional constituyen, en el siglo xxi, los únicos medios legítimos para lograr el reconocimiento de los derechos de los Estados.

Es por ello que nos tocó dedicar una parte importante de nuestra carrera a la práctica de las relaciones internacionales y del derecho internacional y a la acción multilateral. Ellas representan una de nuestras grandes tradiciones republicanas y un elemento consustancial de la identidad exterior y del interés nacional de Chile.

Todo ello fue posible gracias a la formación y el ejemplo que nos dio esta Universidad, que nos acogió y que nos sigue acogiendo.

Muchas gracias. 